\title{
A Static Fracturing Technology to Enhance the Permeability of Coalbed: Mechanical Study
}

\author{
Long Wang $\mathbb{D}^{1},{ }^{1}$ Baohua Guo $\mathbb{D D}^{2,3}$ and Zhaofeng Wang ${ }^{1,3}$ \\ ${ }^{1}$ School of Safety Science and Engineering, Henan Polytechnic University, JiaoZuo 454003, China \\ ${ }^{2}$ School of Energy Science and Engineering, Henan Polytechnic University, JiaoZuo 454003, China \\ ${ }^{3}$ Collaborative Innovation Center of Coal Safety Production of Henan Province, JiaoZuo 454003, China \\ Correspondence should be addressed to Baohua Guo; guobaohua@139.com
}

Received 22 March 2019; Revised 8 May 2019; Accepted 13 May 2019; Published 9 June 2019

Academic Editor: Rafael J. Bergillos

Copyright (c) 2019 Long Wang et al. This is an open access article distributed under the Creative Commons Attribution License, which permits unrestricted use, distribution, and reproduction in any medium, provided the original work is properly cited.

\begin{abstract}
Low permeability of coalbed has always been a main bottleneck impeding the safety production of coal mines and the highefficient gas recovery. A static fracturing technology, relied on hydraulic-driving modules to expand outwards for producing artificial fissures in coalbed, is proposed here for coalbed reservoir stimulation. The mechanical model of borehole fracturing is established to clarify the associated mechanisms for fracturing stimulation based on the elastic-plastic mechanics. The numerical results indicate when the fracturing load is over twice as much as in situ stress, the concentration of hoop stress around borehole would be released and the range of fracturing-induced fissures gradually extends with the rising load. While the lateral stress coefficient of strata rising from 1 to 3 , the stress distribution around borehole evolves from a ring to a saddle shape, resulting in the horizontal extension of fissures in the early stage. According to underground monitoring, a significant improvement of coalbed permeability up to 5 times has been achieved in 16031 tailgate, in Guhanshan coalmine, China.
\end{abstract}

\section{Introduction}

On account of a specific energy structure and a gigantic consumption, China has already been the world's largest coal producer with the output of 3.41 billion tons in 2016, meanwhile suffering serious gas disasters $[1,2]$. State Work Safety Administration of China reported that there were totally 164 gas accidents, killing about 955 people from 2013 to 2016 [3]. Insisting on gas recovery before mining can not only eliminate the danger of coal and gas outbursts during coal production but also offer clean energy and reduce greenhouse gas emissions [4-6]. Gas drainage from deep underground coal mine seems a promising solution for the energy crisis.

However, most of the coalfields in China were formed in Permo-Carboniferous system, experiencing several large-scale tectogenesises, which brought about fragmented coal and mylonitic coal $[7,8]$. Thus, these coalfields are characterized by low permeability $(K \leq 0.005 \mathrm{mD})$, small firmness $(f \leq 1)$, strong adsorption, and high gas pressure $(P \geq 0.74 \mathrm{MPa})$ [9]. Up to date, many analytical models [10-14] were proposed to describe the dynamic changes in coalbed permeability during gas drainage period under uniaxial compression conditions. These models show coal permeability reduces with the increase of in situ stress, representing a negative exponential function as the coalbed buried depth. On the other hand, coal permeability is also dominated by matrix porosity and fractures with a unique cleat system, including size, spacing, connectivity, orientation, and the aperture of mineral infill [15]. Under the increased effective stress action, gas flow channels within these cleats become narrower, even close completely. Thus, the permeability decreases dramatically. However, the existing permeability models, on the assumptions of uniaxial strain and constant vertical stress, have not taken into account the original stress state and the varying of cleat 
compressibility and thus are unsuitable in the field application.

On the other hand, conventional methods of gas drainage face difficulties: long preextraction time, quick reduction in gas flowrate, and huge drilling project. The reservoir stimulation techniques are needed to enhance coalbed permeability, mainly including hydraulic fracturing [16-19], hydraulic flushing $[20,21]$, presplitting blasting [22-25], liquid $\mathrm{CO}_{2}$ phase-transition fracturing [26-29], and $\mathrm{CO}_{2}$ injection [30-32]. These measures were implemented in coal mines and achieved fine effects. However, there is still a lack of general applicability owing to various hosting characteristics of coalbed occurrence. For example, hydraulic fracturing with complicated equipment is not applicable for soft coalbeds with the firmness below 0.8. However, hydraulic flushing easily causes borehole collapse to bury drilling tools and even triggers the coal and gas outburst with an inappropriate pressure of flushing. Moreover, all of hydraulic operations usually make a muddy and rugged working place. As for presplitting blasting in deep hole, it has a strong explosive force, but the charge quantity of explosives is hard to control and there is a hidden danger when detonator once misses fire. The greater adsorption potential of carbon dioxide $\left(\mathrm{CO}_{2}\right)$ in coal is an appealing fact in relation to enhanced coalbed methane recovery (ECBM) and the longterm $\mathrm{CO}_{2}$ storage. However, the associated coal structure modification, particularly by coal matrix swelling, and the $\mathrm{CO}_{2}$ flow ability through the coalbed bring many uncertainties to the injection operation [33-35]. Further, many factors directly affect the production of $\mathrm{CO}_{2}-\mathrm{ECBM}$ in respect to its capacity, injectivity, plume movement, saturation period, and leakage assessment.

A static fracturing technology, relied on hydraulicdriving modules to expand outwards for producing a large amount of artificial fissures in coalbed, was proposed here. Firstly, the fracturing model was established based on the elastic-plastic mechanics. Then, the effect of fracturing load on stress distribution and the initial fissure position were discussed by using FLAC ${ }^{3 \mathrm{D}}$ software. Eventually, three groups of fracturing tests were conducted in 16031 tailgate tunnel, Guhanshan coalmine, to verify the permeability improvement of No. 2-1 coalbed.

\section{Engineering Background}

2.1. Test Site. The field trials of the static fracturing technology have been conducted in Guhanshan coalmine, located in the northeast of Jiaozuo coalfield. Nowadays, the coalmine is mainly recovering No. 2-1 coalbed, and the design production capacity is about 1.2 million tons of anthracite annually. The average thickness of No. 2-1 coalbed is approximately $2.8 \mathrm{~m}$, with the dip angle of $12^{\circ} \sim 17^{\circ}$. According to identification results over the years, the maximum of relative gas emission quantity reaches $33.32 \mathrm{~m}^{3} / \mathrm{t}$ and the absolute gas emission quantity is $75.59 \mathrm{~m}^{3} / \mathrm{min}$. Undoubtedly, Guhanshan coalmine faces a high risk of coal and gas outburst both in driving and mining periods.
In order to extract gas gushed from No. 16031 working face, a single row of drainage boreholes was arranged in the range of 10 680 $\mathrm{m}$ of the lower rib of No. 16031 tailgate. The aperture of borehole is perpendicular to the middle line of the tunnel. The depth of borehole is $70 \mathrm{~m}$, and the initial drilling height is $1.2 \mathrm{~m}$ away from the floor within the deviation of $\pm 10 \mathrm{~cm}$. The angles of odd and even borehole are $-2^{\circ}$ and $-3^{\circ}$, respectively. The borehole spaces are, respectively, $0.8 \mathrm{~m}$ and $1.6 \mathrm{~m}$ in the range of $10-74 \mathrm{~m}$ and of 74-680 $\mathrm{m}$ away from the open-off cut. Three groups of the static fracturing tests were implemented as shown in Figure 1.

2.2. Underground Trial Setup. A static fracturing equipment (Figure 2) is mainly composed of a fracturing bit, an outburst preventer, a driller, and a hydraulic pump. The planform of the fracturing bit includes a high pressure wire-rope capsule, inner and outer fracturing modules, and antifriction cushions. Firstly, the fracturing bit was placed in the preset site of borehole after drilling up to the coalbed. When adjusting the pressure of hydraulic pump to $25 \mathrm{MPa}$, the wire-rope capsule immediately swelled up and pushed both inner and outer fracturing modules to gradually expand outwards the hole wall, thus fissures generating around borehole. The wire-rope capsule can automatically reset by shutting off the hydraulic pump after completing the fracturing operation, and then, it was handily removed from the borehole. Unlike most traditional blasting techniques, the fracturing equipment exerts static loads on coalbed by virtue of the incompressibility and fluidity of hydraulic oil, thus realizing the safe and controllable work.

\section{Methodology}

3.1. Mechanical Model of Borehole Fracturing. The static fracturing technology aims to relieve or even eliminate the hoop stress concentration around borehole to produce more gas flow channels by exerting a high-pressure load on the hole wall. Providing the surrounding coal around borehole is submitted to the homogenous elastic-plastic material, the borehole model should be regarded as a microcircular tunnel complied with the Mohr-Coulomb criterion. Since the axial length and the buried depth of borehole are much more than 20 times its diameter, the model is simplified as the plane strain model as shown in Figure 3 [36].

\subsubsection{Elastic-Plastic Solutions of the Fracturing Model.} Providing the cohesion and the friction angle of coal are always constant and the lateral coefficient $\lambda=1$, the elasticplastic solutions of resultant stress should be discussed on the two conditions.

If $\sigma_{\theta}<\sigma_{\mathrm{r}}$, Mohr-Coulomb criterion is described as follows:

$$
\sigma_{\theta}=\xi \sigma_{\mathrm{r}}+\sigma_{\mathrm{c}}
$$




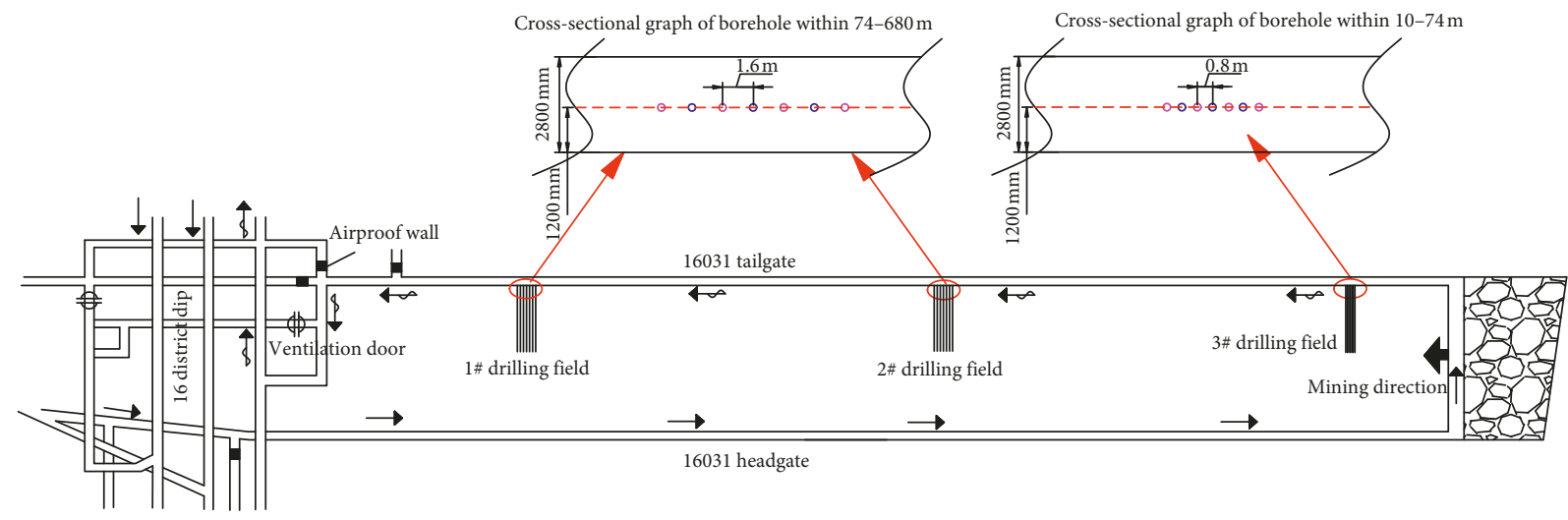

○- Fracturing borehole

o- Measurement borehole

FIgURE 1: Location of 16031 tailgate and drilling layout.

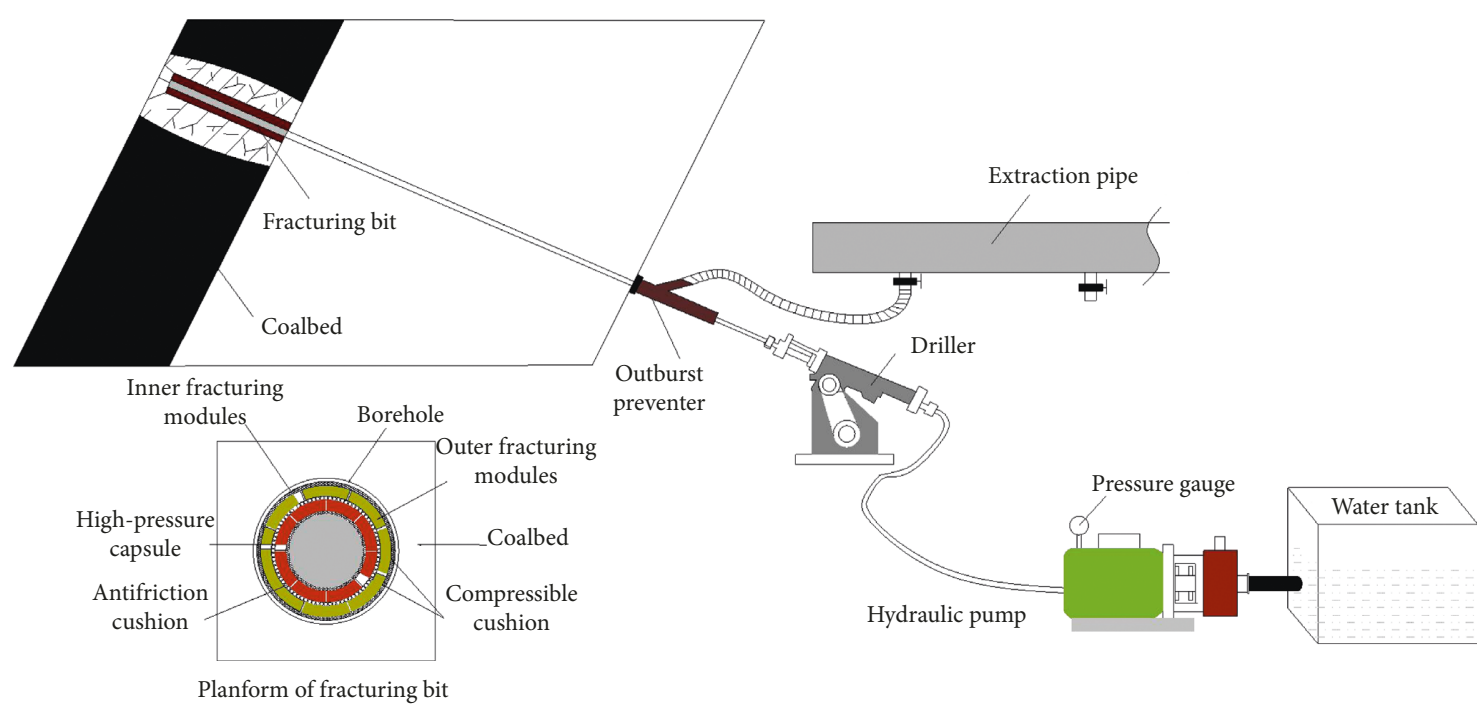

Figure 2: Operation chart of static fracturing technology.

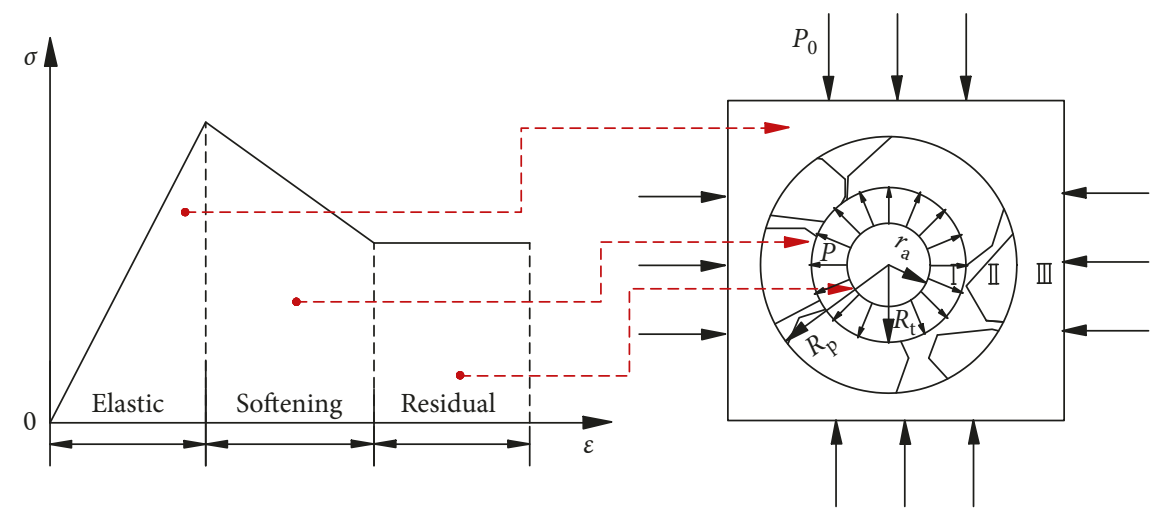

FIgURE 3: Mechanical model of borehole fracturing.

where $\sigma_{\mathrm{r}}$ is the radial stress of a point around borehole; $\sigma_{\theta}$ is the hoop stress of a point around borehole; $P$ is the fracturing load exerting on hole wall; $P_{0}$ is the in situ stress; $r$ is the distance of a point to the hole wall; $r_{\mathrm{a}}$ is the borehole radius; $\xi=1+\sin \varphi / 1-\sin \varphi$; and $\sigma_{c}=2 c \cos \varphi / 1-\sin \varphi$. Putting Mohr-Coulomb criterion into the equation of static equilibrium $\left(\sigma_{\theta p}=r\left(d \sigma_{\mathrm{r}} / d r\right)+\sigma_{\mathrm{rp}}\right)$, the solutions can be written as 


$$
\left\{\begin{array}{l}
\sigma_{\theta p}=\left(\frac{\sigma_{\mathrm{c}}}{1-\xi}\right)+C r^{\xi-1}, \\
\sigma_{\mathrm{rp}}=\frac{1}{\xi}\left(\left(\frac{\xi \sigma_{\mathrm{c}}}{1-\xi}\right)+C r^{\xi-1}\right) .
\end{array}\right.
$$

The integration constant $C$ can be determined by inputting the boundary condition (when $r=r_{\mathrm{a}}, \sigma_{\mathrm{rp}}=P$ ).

$$
C=\left(p \xi+\frac{\xi \sigma_{\mathrm{c}}}{\xi-1}\right) \cdot\left(\frac{1}{r_{\mathrm{a}}}\right)^{\xi-1}
$$

Thus, the elastic-plastic solutions of stress can be expressed as follows:

$$
\left\{\begin{array}{c}
\sigma_{\theta p}=\frac{\sigma_{\mathrm{c}}}{\xi-1}\left[\xi\left(\frac{r}{r_{\mathrm{a}}}\right)^{\xi-1}-1\right]+p\left(\frac{r}{r_{\mathrm{a}}}\right)^{\xi-1}, \\
\sigma_{\mathrm{rp}}=\frac{\sigma_{\mathrm{c}}}{\xi-1}\left[\left(\frac{r}{r_{\mathrm{a}}}\right)^{\xi-1}-1\right]+p\left(\frac{r}{r_{\mathrm{a}}}\right)^{\xi-1},
\end{array}\right.
$$

where $\sigma_{\mathrm{rp}}$ is the radial stress of a point on the plastic zone; $\sigma_{\theta p}$ is the hoop stress of a point on the plastic zone; and $\sigma_{c}$ is the compressive stress. Since the radial and the hoop stresses on the plastic boundary well meet the elastic stress condition $\left(\sigma_{\theta p}+\sigma_{\mathrm{rp}}=2 p_{0}\right)$, the radius of the plastic zone $R_{\mathrm{p}}$ is expressed as follows:

$$
R_{\mathrm{p}}=r_{\mathrm{a}}\left[\frac{\left[2 p_{0}-p(\xi+1)\right](\xi-1)+2 \sigma_{\mathrm{c}}}{\sigma_{\mathrm{c}}(\xi+1)}\right]^{1 /(\xi-1)}
$$

When $\sigma_{\theta}<\sigma_{\mathrm{r}}$, Mohr-Coulomb criterion is represented as follows:

$$
\sigma_{\mathrm{r}}=\xi \sigma_{\theta}+\sigma_{\mathrm{c}}
$$

Putting Mohr-Coulomb criterion into the equation of static equilibrium, we can also get the differential equation:

$$
\frac{\partial \sigma_{\mathrm{rp}}}{\partial r}+\frac{(\xi-1) \sigma_{\mathrm{rp}}+\sigma_{\mathrm{c}}}{r \xi}=0
$$

The solution of differential equation is expressed as follows:

$$
\sigma_{\mathrm{rp}}=\frac{\sigma_{\mathrm{c}} r}{1-\xi}+C r^{(1-\xi) / \xi}
$$

The integration constant $C$ can be determined by inputting the boundary condition (when $r=r_{\mathrm{a}}, \sigma_{\mathrm{rp}}=p$ ):

$$
C=\left(p+\frac{\sigma_{\mathrm{c}}}{\xi-1}\right) \cdot r_{\mathrm{a}}^{(\xi-1) / \xi} \text {. }
$$
as

Thus, the radial stress on the plastic zone can be written

$$
\sigma_{\mathrm{rp}}=p\left(\frac{r_{\mathrm{a}}}{r}\right)^{(\xi-1) / \xi}+\frac{\sigma_{\mathrm{c}}}{1-\xi}\left[1-\left(\frac{r_{\mathrm{a}}}{r}\right)^{(\xi-1) / \xi}\right] .
$$

The hoop stress is expressed as follows:

$$
\sigma_{\theta p}=\frac{p}{\xi}\left(\frac{r_{\mathrm{a}}}{r}\right)^{(\xi-1) / \xi}+\frac{\sigma_{\mathrm{c}}}{1-\xi}\left[1-\frac{1}{\xi}\left(\frac{r_{\mathrm{a}}}{r}\right)^{(\xi-1) / \xi}\right] .
$$

The hoop stress on the plastic boundary can be determined with inputting condition:

$$
\sigma_{\theta p}=\frac{\sigma_{\mathrm{c}}}{1-\xi}+\frac{1}{\xi}\left(p+\frac{\sigma_{\mathrm{c}}}{\xi-1}\right)=\frac{1}{\xi}\left(p-\sigma_{\mathrm{c}}\right) .
$$
follows:

Therefore, the radius of plastic zone is represented as

$$
R_{\mathrm{p}}=r_{\mathrm{a}}\left[\frac{\left[(1-\xi) p-\sigma_{\mathrm{c}}\right](\xi+1)}{2 \xi\left[(1-\xi) p_{0}-\sigma_{\mathrm{c}}\right]}\right]^{\xi /(\xi-1)}
$$

When $P>2 P_{0}, \sigma_{\theta p}<0$, which demonstrates the tensile stress generated on the hoop direction of surrounding coal. Therefore, the tensile fissure radius $R_{\mathrm{t}}$ can be determined by inputting the condition $\left(\sigma_{\theta p}=-\sigma_{\mathrm{t}}\right)$

$$
\begin{gathered}
-\sigma_{\mathrm{t}}=p_{0}+\left(p_{0}-p\right)\left(\frac{r_{\mathrm{a}}}{r}\right)^{2}, \\
R_{\mathrm{t}}=r_{\mathrm{a}}\left(\frac{p-p_{0}}{p_{0}+\sigma_{\mathrm{t}}}\right)^{1 / 2} .
\end{gathered}
$$

3.1.2. Initial Position of Radial Fissures. When the stresses distribute nonuniformly $(\lambda \neq 1)$, the hoop stress on hole wall $\sigma_{\theta}$ is determined based on elastic mechanics as follows:

$$
\left.\sigma_{\theta}\right|_{r=r_{0}}=(1+\lambda) p_{0}+2(1-\lambda) p_{0} \cos 2 \theta-p
$$

Two cases (the azimuth $\theta=0^{\circ} / 90^{\circ}$ ) are also discussed here.

Firstly, providing $\theta=0^{\circ}$, the hoop stress on hole wall is shown as follows:

$$
\left.\sigma_{\theta}\right|_{r=r_{0}, \theta=0}=(3-\lambda) p_{0}-p .
$$

To satisfy the generation condition of tensile fissures around borehole, the hoop stress $\sigma_{\theta}$ must meet $\sigma_{\theta}<0$; $\left|\sigma_{\theta}\right|>R_{\mathrm{t}}$. Thus, the fracturing load $P$ should meet the condition as follows:

$$
p \geq(3-\lambda) p_{0}+R_{\mathrm{t}}
$$

While providing $\theta=90^{\circ}$, the hoop stress on hole wall is represented as follows:

$$
\left.\sigma_{\theta}\right|_{r=r_{0}, \theta=90}=(3 \lambda-1) P_{0}-P \text {. }
$$

The fracturing load $P$ should meet the following condition to produce tensile fissures:

$$
p \geq(3 \lambda-1) p_{0}+R_{\mathrm{t}} .
$$

Accordingly, providing $\lambda>1$, it is easier for the fracturing load $P$ to meet equation (18). Thus, the tensile fissures initially occur in the horizontal direction of borehole. While $\lambda<1$, it is easier for the fracturing load $P$ to meet equation (20); thus, tensile fissures are generated in the vertical direction of the borehole. It should be noted that both the 
coalbed occurrence and the mining disturbance have great impacts on the positions of radial fissures in the field.

3.2. Numerical Simulation. The numerical model was established based on the geological and mining conditions of Guhanshan coalmine. According to the borehole histogram, rock strata were regarded as isotropic material without considering the influences of structural plane, interlayer, and groundwater. In the model, a borehole $(\Phi=90 \mathrm{~mm})$ was drilled in the middle of the tunnel right side. Owing to the buried depth of tunnel of $400 \mathrm{~m}$, the stress of $10 \mathrm{MPa}$ was applied on the top boundary to simulate the gravity of the overburden strata. Besides, the bottom boundary of the model was fixed, and the roller boundary was adopted on the lateral of the model (Figure 4).

\section{Results and Discussion}

4.1. Effect of the Fracturing Load on Stress Distribution around Borehole. To investigate the effects of fracturing load on stress distribution around borehole, the loads of $15 \sim 30 \mathrm{MPa}$ were, respectively, exerted on hole wall. The stress and plastic zone distribution under different loads are shown in Figures 5 and 6.

Figure 5 indicates with the fracturing load rising from $15 \mathrm{MPa}$ to $30 \mathrm{MPa}$, the radial compressive stresses on hole wall gradually increase, which are $13.73 \mathrm{MPa}, 17.46 \mathrm{MPa}$, $20.44 \mathrm{MPa}$, and $24.91 \mathrm{MPa}$, respectively. On the other hand, the hoop stress on hole wall decreases from $6.09 \mathrm{MPa}$ to 2.12 MPa when the fracturing load rises up to $20 \mathrm{MPa}$. After the load reaches $24 \mathrm{MPa}$, the hoop compressive stresses gradually turn to become the tensile stresses and constantly increase with the load rising from $24 \mathrm{MPa} 30 \mathrm{MPa}$, which are $1.06 \mathrm{MPa}$ and $5.81 \mathrm{MPa}$, respectively. In this case, the hoop stress concentration around borehole is absolutely eliminated when the fracturing load is over twice of in situ stress.

Figure 6 indicates compression-shear fissures mainly arise around borehole when the fracturing load is less than $20 \mathrm{MPa}$ and the plastic-damage zone extends with a rising load. When the load is over $24 \mathrm{MPa}$, tensile fissures start to occur around borehole and the damage range would significantly extend with the rising load. Under the combined effects of tensile fissures and compression-shear fissures, the fissure range around borehole is considerably larger than the original one.

4.2. Effect of the Lateral Coefficient on Fracturing. In the field, the horizontal stress in strata is always larger than the vertical stress under the action of tectonic movement. Thus, the characteristics of stress distribution around borehole were discussed under different lateral coefficients as shown in Figure 7. The fracturing load of $30 \mathrm{MPa}$ was equally applied in each model.

Figure 7 depicts the stress distribution around borehole gradually evolves from a ring to the saddle shape when the lateral coefficient of coalbed rises from 1 to 3 . The tensile stresses in horizontal direction increase with a rising lateral

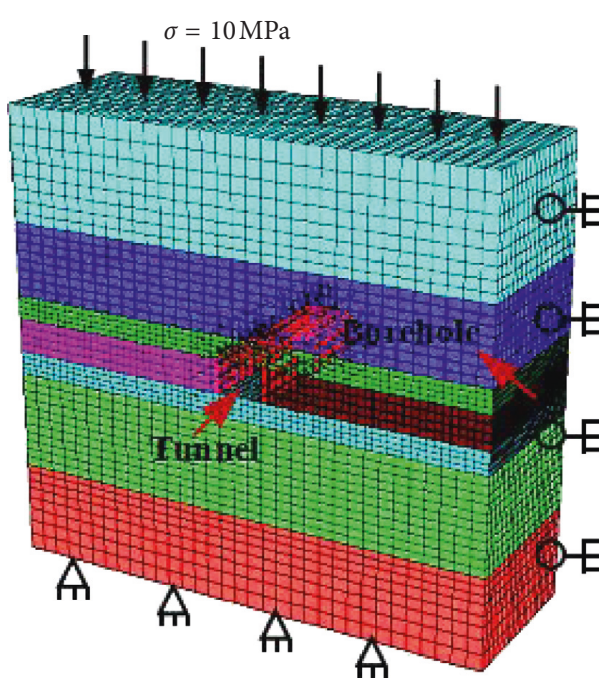

Figure 4: Numerical model.

coefficient, which are $5.81,7.92,10.21$, and $14.87 \mathrm{MPa}$, respectively. When the lateral coefficients are 2 and 3 , the hoop compressive stress mainly concentrates in the vertical direction and the peak compressive stresses are 16.84 and $29.47 \mathrm{MPa}$, respectively, thus generating more fracturinginduced damage in the horizontal direction. At this time, the occurrence of fissures is no longer randomly distributed. Besides, the peak radial stresses in the vertical direction gradually increase with the rising lateral coefficient, which are 24.91, 26.21, 26.75, and $39.99 \mathrm{MPa}$, respectively. It would cause larger horizontal displacements owing to Poisson's effect.

4.3. Verification of Fracturing Effect. In order to determine the difference of permeability coefficient of coalbed before and after fracturing, a cross-borehole was firstly drilled and sealed to measure the residual gas pressure of No. 2-1 coalbed. Then, an orifice flowrate was installed one day after the gas pressure gauge removed to measure the daily gas flowrate, and the measurement duration was recorded. The permeability coefficient can be evaluated based on the theory of unstable radial gas flow in coalbed as follows [37]

$$
\lambda=A^{1.39} B^{1 / 2.56},
$$

where $\lambda$ is the permeability coefficient; $A=q r / P_{0}^{2}-P_{1}^{2}$; $B=4 P_{0}^{1.5} / \alpha \cdot r^{2} ; P_{0}$ is the gas pressure of coalbed; $P_{1}$ is the atmospheric pressure; $q$ is the gas flowrate through unit area; $r$ is the borehole radius; and $\alpha$ is the gas content coefficient.

Figure 8 indicates the number of radial fissures around borehole increases and the coal mass becomes loose after fracturing, resulting in the permeability of coalbed significantly improved. Then, with the increase of drainage time, the shrinkage deformation inevitably happens in coal mass and the fissures would be gradually closed. The permeability coefficient tends to be stable after one month, which is increased by $4.7 \sim 5.8$ times.

Drainage parameters (gas concentration, drainage pressure of the system, the diameter of drainage pipe, and 


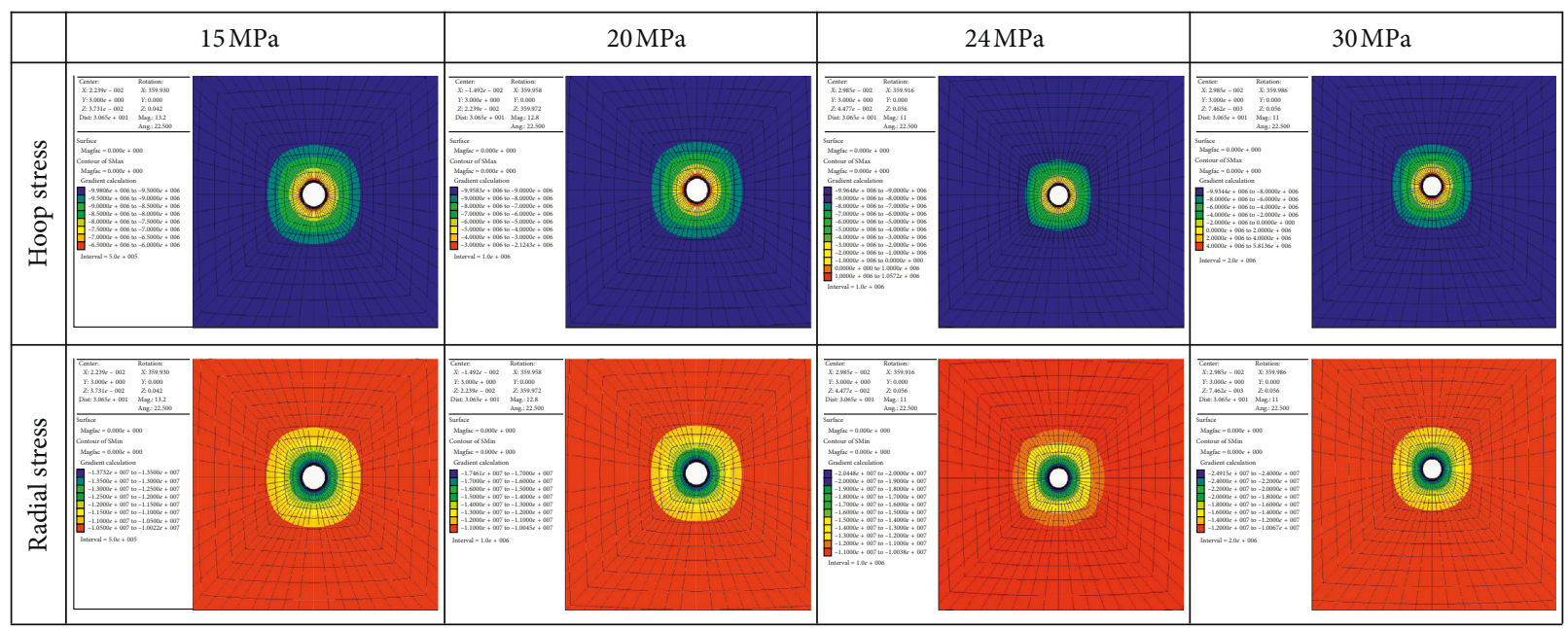

FIGURE 5: Stress contour under fracturing loads of 15 30 MPa.

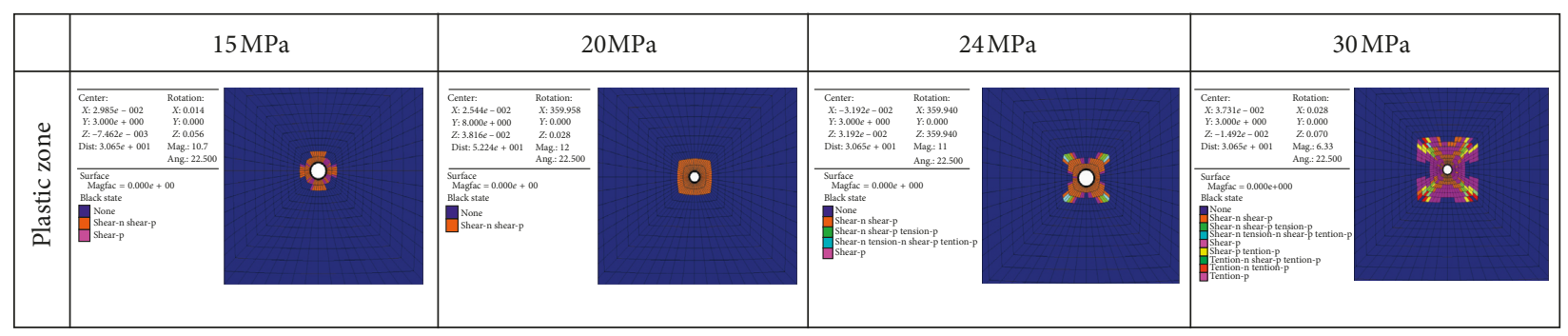

Figure 6: Plastic zone distribution under the load of 15 30 MPa.

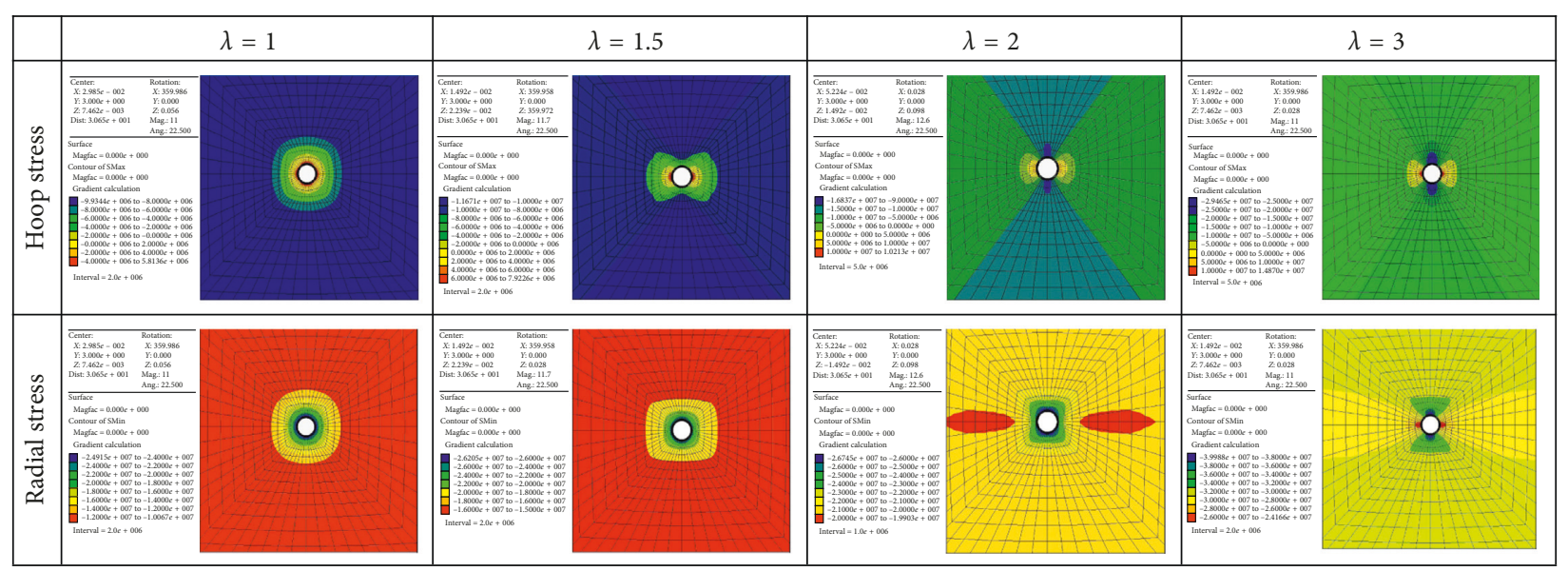

Figure 7: Stress contour around borehole under different lateral coefficients.

the flow velocity of gas) of the three groups of measurement; boreholes were totally monitored for 84 days so as to determine the variation of gas flowrate before and after fracturing. Figure 9 gives the changes of flowrate and concentration of gas of $1 \#$ drilling group before and after the fracturing operation.

For the traditional drainage method, the gas flow started at the formation of borehole and the results indicate clearly that the gas flowrate gradually reduced in a short period of 26 days after the beginning of gas drainage.
However, by fracturing operation, a large amount of absorbed gas would be desorbed into free state with the improvement of the permeability of coalbed, resulting in a sharp increase in gas drainage concentration. The flowrate of mixed gas also increased owing to the fissure formation caused by fracturing, which demonstrates the significant improvement in efficiency of gas drainage by using the fracturing technology. According to the statistical analysis of each measurement borehole, after fracturing, the gas drainage concentration increased by 2.16 times on average, 


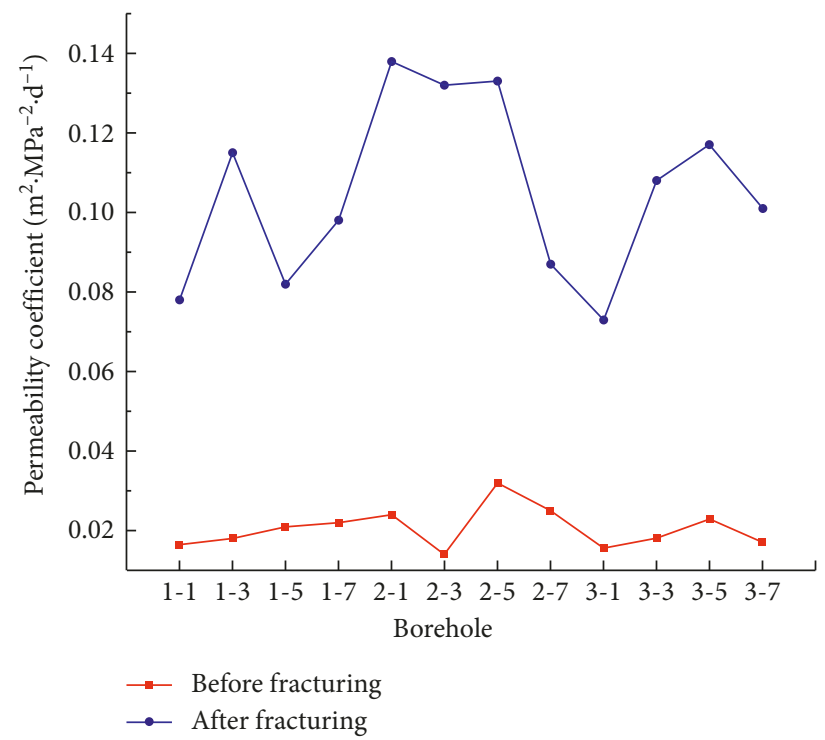

Figure 8: Changes of permeability coefficient of coalbed.

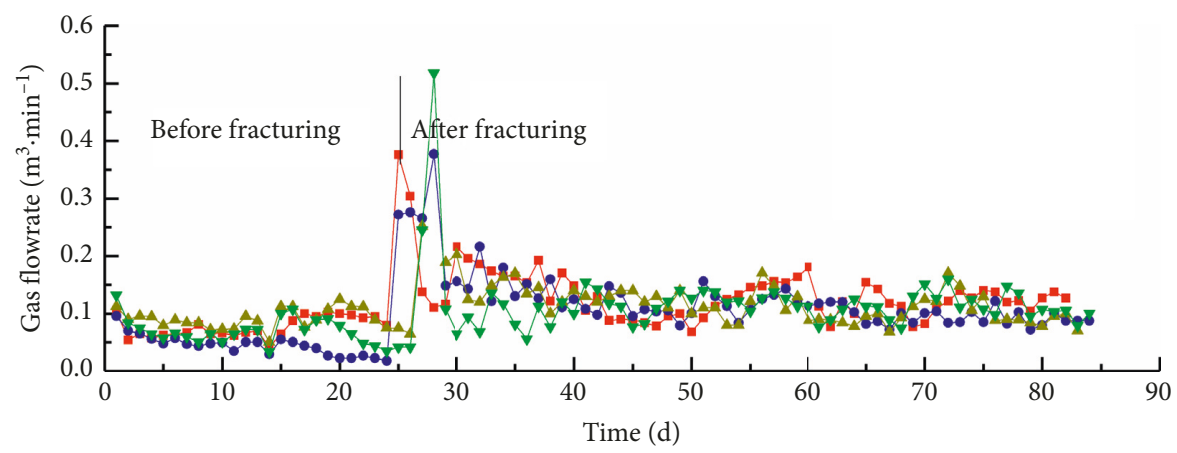

(a)

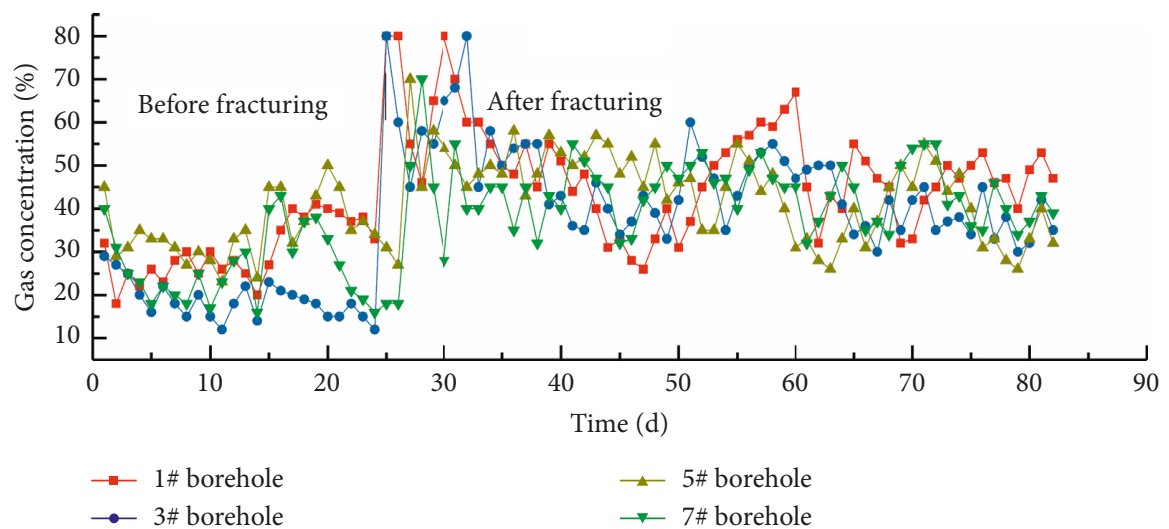

(b)

Figure 9: Curves of gas flowrate and gas concentration.

and the pure flowrate of gas recovery flow increased by 2.05 times.

\section{Conclusions}

A static fracturing technology to enhance the permeability of coalbed is proposed here for the high efficiency of gas recovery. The mechanism of borehole fracturing is clarified based on the mechanical analysis and numerical modeling. The results demonstrate the following (1) When the fracturing load is over twice as much as in situ stress, the concentration of hoop stress around borehole is released and there are more tensile fissures generated with a rising load, which results in the promotion in coal permeability. (2) When the lateral coefficient $>1$, tensile fissures are generated in the horizontal direction of borehole and vice versa. The 
stress distribution around borehole gradually evolves from a ring to the saddle shape with the lateral coefficient rising from 1 3. (3) After the fracturing operation, the gas drainage concentration increased by 2.16 times on average, and the pure flowrate of gas recovery flow increased by 2.05 times.

In the future, more experimental effects and field applications are needed in order to understand the evolvement of fracturing-induced fissures and the characteristics of gas flow in coalbed, associated with different drainage periods by the static fracturing stimulation.

\section{Data Availability}

The research data used to support the findings of this study are included within the article. Request for more details should be made to the corresponding author.

\section{Conflicts of Interest}

The authors declare that they have no conflicts of interest.

\section{Acknowledgments}

We appreciate Guhanshan coalmine for providing experiment support for our study and are grateful to the China National Natural Science Foundation (Grant no. 51109076).

\section{Supplementary Materials}

The graphical abstract: static fracturing system for ECBM and the effect on gas drainage. (Supplementary Materials)

\section{References}

[1] British Petroleum Company, BP Statistical Review of World Energy 2016, BP plc, London, 2016, http://indiaen vironmentportal.org.in/files/file/bp-statistical-review-of-worldenergy-2016.pdf.

[2] Y.-P. Cheng, L. Wang, and X.-L. Zhang, "Environmental impact of coal mine methane emissions and responding strategies in China," International Journal of Greenhouse Gas Control, vol. 5, no. 1, pp. 157-166, 2011.

[3] China State Administration of Work Safety, Coal Mine Accidents Reporting in China 2013-2016, China State Administration of Work Safety, China, 2014.

[4] H. Guo, L. Yuan, B. Shen, Q. Qu, and J. Xue, "Mining-induced strata stress changes, fractures and gas flow dynamics in multi-seam longwall mining," International Journal of Rock Mechanics and Mining Sciences, vol. 54, pp. 129-139, 2012.

[5] Y. P. Cheng, J. H. Fu, and Q. X. Yu, "Development of gas recovery technology in coal mines of China," Journal of Mining \& Safety Engineering, vol. 26, pp. 127-139, 2009.

[6] H. Liu and Y. Cheng, "The elimination of coal and gas outburst disasters by long distance lower protective seam mining combined with stress-relief gas extraction in the Huaibei coal mine area," Journal of Natural Gas Science and Engineering, vol. 27, pp. 346-353, 2015.

[7] X. Su, Y. Feng, J. Chen, and J. Pan, "The characteristics and origins of cleat in coal from Western North China," International Journal of Coal Geology, vol. 47, no. 1, pp. 51-62, 2001.
[8] K. X. Huang and Y. C. Xia, Outline of Structural Coal Control, China Coal Industry Press, Beijing, China, 1991.

[9] D. Y. Cao, Z. Y. Lin, Z. H. Zheng, and J. Q. Tan, "Coal field structures and potential evaluation of coal resources in China," Advanced Materials Research, vol. 356-360, pp. 2937-2940, 2011.

[10] I. Palmer and J. Mansoori, "How permeability depends on stress and pore pressure in coalbeds: a new model," SPE Reservoir Evaluation \& Engineering, vol. 1, no. 6, pp. 539-544, 1998.

[11] J.-Q. Shi and S. Durucan, "A model for changes in coalbed permeability during primary and enhanced methane recovery," SPE Reservoir Evaluation \& Engineering, vol. 8, no. 4, pp. 291-299, 2005.

[12] S. Durucan and J. S. Edwards, "The effects of stress and fracturing on permeability of coal," Mining Science and Technology, vol. 3, no. 3, pp. 205-216, 1986.

[13] Z. Pan and L. D. Connell, "Modelling permeability for coal reservoirs: a review of analytical models and testing data," International Journal of Coal Geology, vol. 92, pp. 1-44, 2012.

[14] L. D. Connell, M. Lu, and Z. Pan, "An analytical coal permeability model for tri-axial strain and stress conditions," International Journal of Coal Geology, vol. 84, no. 2, pp. 103-114, 2010

[15] S. E. Laubach, R. A. Marrett, J. E. Olson, and A. R. Scott, "Characteristics and origins of coal cleat: a review," International Journal of Coal Geology, vol. 35, no. 1-4, pp. 175-207, 1998.

[16] T. H. Yang, L. G. Tham, C. A. Tang, Z. Z. Liang, and Y. Tsui, "Influence of heterogeneity of mechanical properties on hydraulic fracturing in permeable rocks," Rock Mechanics and Rock Engineering, vol. 37, no. 4, pp. 251-275, 2004.

[17] Q. Li, B. Lin, and C. Zhai, "The effect of pulse frequency on the fracture extension during hydraulic fracturing," Journal of Natural Gas Science and Engineering, vol. 21, pp. 296-303, 2014.

[18] F. Yan, B. Lin, C. Zhu et al., "A novel ECBM extraction technology based on the integration of hydraulic slotting and hydraulic fracturing," Journal of Natural Gas Science and Engineering, vol. 22, pp. 571-579, 2015.

[19] J. Zhang, "Numerical simulation of hydraulic fracturing coalbed methane reservoir," Fuel, vol. 136, pp. 57-61, 2014.

[20] Y. Zhang and Q. Zou, "A prediction model for the slot depth of high pressure water jet," Results in Physics, vol. 11, pp. 1105-1109, 2018.

[21] T. Lu, H. Yu, T. Zhou, J. Mao, and B. Guo, "Improvement of methane drainage in high gassy coal seam using waterjet technique," International Journal of Coal Geology, vol. 79, no. 1-2, pp. 40-48, 2009.

[22] Z. Zhu, B. Mohanty, and H. Xie, "Numerical investigation of blasting-induced crack initiation and propagation in rocks," International Journal of Rock Mechanics and Mining Sciences, vol. 44, no. 3, pp. 412-424, 2007.

[23] Z. Zhu, H. Xie, and B. Mohanty, "Numerical investigation of blasting-induced damage in cylindrical rocks," International Journal of Rock Mechanics and Mining Sciences, vol. 45, no. 2, pp. 111-121, 2008.

[24] Z. F. Wang, L. Wang, and X. J. Chen, "Application of deep borehole pre-creaking blasting to coal mining in high gassy and ultra thick seam," Coal Science Technology, vol. 36, pp. 31-34, 2008.

[25] W. C. Zhu, C. H. Wei, S. Li, J. Wei, and M. S. Zhang, "Numerical modeling on destress blasting in coal seam for 
enhancing gas drainage," International Journal of Rock Mechanics and Mining Sciences, vol. 59, pp. 179-190, 2013.

[26] Z. F. Wang, X. M. Sun, T. K. Lu, and Y. B. Han, "Experiment research on strengthening gas drainage effect with fracturing technique by liquid $\mathrm{CO}_{2}$ phase transition," Journal of Henan Polytechnic University (Natural Science), vol. 34, pp. 1-5, 2015.

[27] T. Lu, Z. Wang, H. Yang, P. Yuan, Y. Han, and X. Sun, "Improvement of coal seam gas drainage by underpanelcross-strata stimulation using highly pressurized gas," International Journal of Rock Mechanics and Mining Sciences, vol. 77, pp. 300-312, 2015.

[28] H. Chen, Z. Wang, X. Chen, X. Chen, and L. Wang, "Increasing permeability of coal seams using the phase energy of liquid carbon dioxide," Journal of $\mathrm{CO}_{2}$ Utilization, vol. 19, pp. 112-119, 2017.

[29] V. Vishal, "Saturation time dependency of liquid and supercritical $\mathrm{CO}_{2}$ permeability of bituminous coals: implications for carbon storage," Fuel, vol. 192, pp. 201-207, 2017.

[30] V. Vishal, "In-situ disposal of $\mathrm{CO}_{2}$ : liquid and supercritical $\mathrm{CO}_{2}$ permeability in coal at multiple down-hole stress conditions," Journal of $\mathrm{CO}_{2}$ Utilization, vol. 17, pp. 235-242, 2017.

[31] C. R. Clarkson and R. M. Bustin, "Binary gas adsorption/ desorption isotherms: effect of moisture and coal composition upon carbon dioxide selectivity over methane," International Journal of Coal Geology, vol. 42, no. 4, pp. 241-271, 2000.

[32] H. Qu, J. Liu, Z. Pan, Y. Peng, F. Zhou, and F. J. Zhou, "Simulation of coal permeability under non-isothermal $\mathrm{CO}_{2}$ injection," International Journal of Oil, Gas and Coal Technology, vol. 15, no. 2, pp. 190-215, 2017.

[33] V. Vishal, B. Mahanta, S. P. Pradhan, T. N. Singh, and P. G. Ranjith, "Simulation of $\mathrm{CO}_{2}$ enhanced coalbed methane recovery in Jharia coalfields, India," Energy, vol. 159, pp. 1185-1194, 2018.

[34] K. S. Ranathunga, M. S. A. Perera, P. G. Ranjith, T. D. Rathnaweera, and X. G. Zhang, "Effect of coal rank on $\mathrm{CO}_{2}$ adsorption induced coal matrix swelling with different $\mathrm{CO}_{2}$ properties and reservoir depths," Energy \& Fuels, vol. 31, no. 5, pp. 5297-5305, 2017.

[35] M. S. A. Perera, "A comprehensive overview of $\mathrm{CO}_{2}$ flow behaviour in deep coalbeds," Energies, vol. 11, no. 4, p. 906, 2018.

[36] M. Q. You, "Study of mathematical equation and parameter determination of strength criteria for rock," Chinese Journal of Rock Mechanics and Engineering, vol. 29, pp. 2173-2184, 2010.

[37] Z. F. Wang and Q. X. Dong, "Research status sbout determining permeability coefficient in coal seam," Safety in Coal Mines, vol. 46, no. 6, pp. 16-19, 2015. 


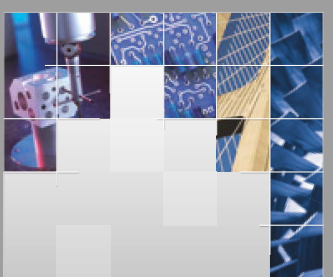

\section{Enfincering}
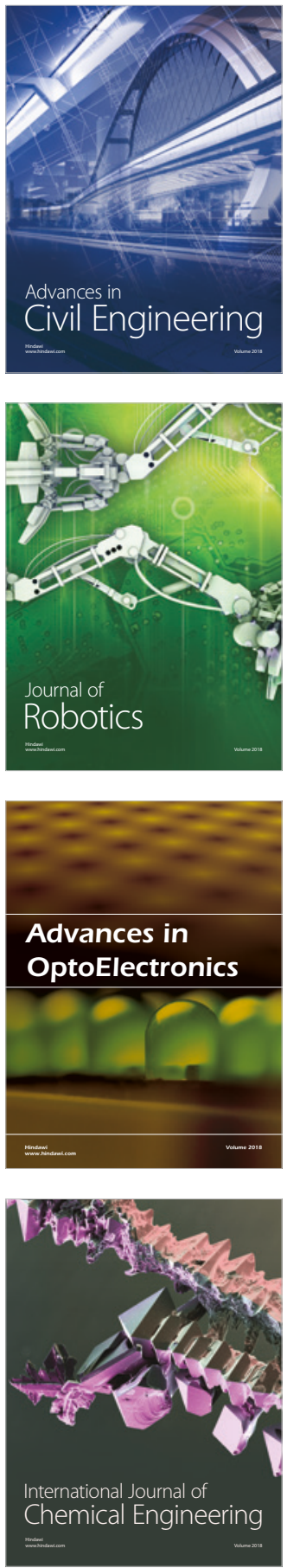

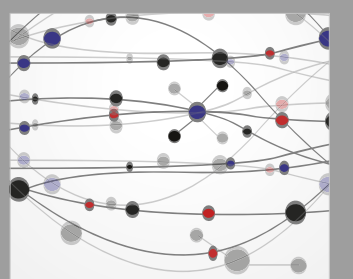

\section{Rotating \\ Machinery}

The Scientific World Journal

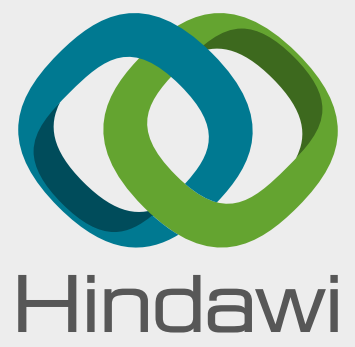

Submit your manuscripts at

www.hindawi.com
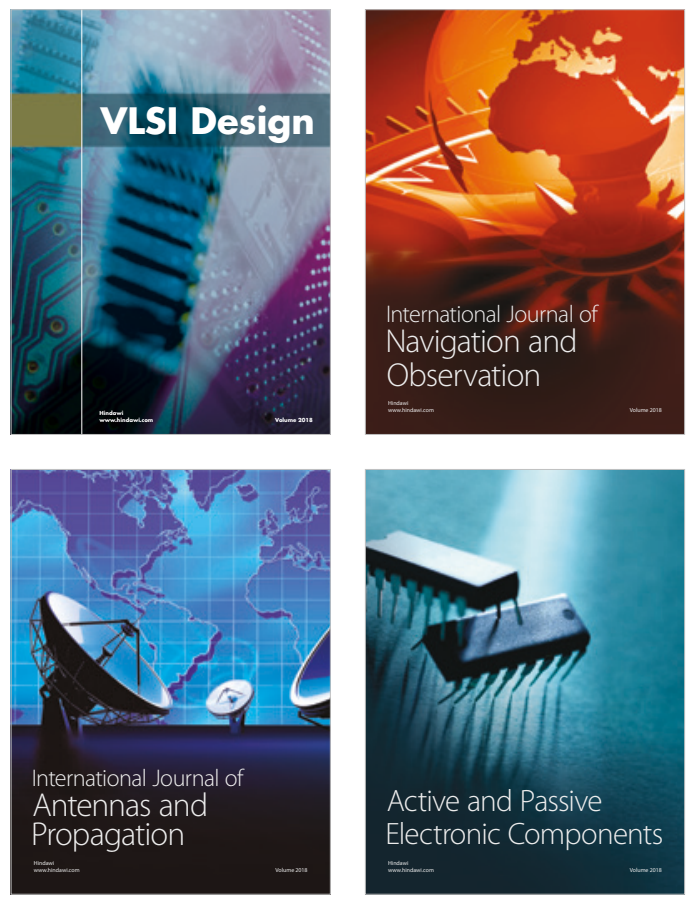
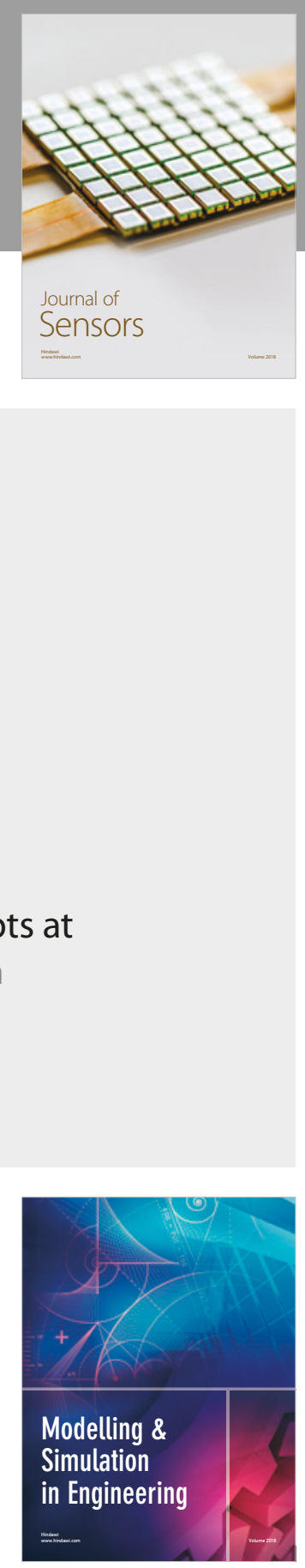

\section{Advances \\ Multimedia}
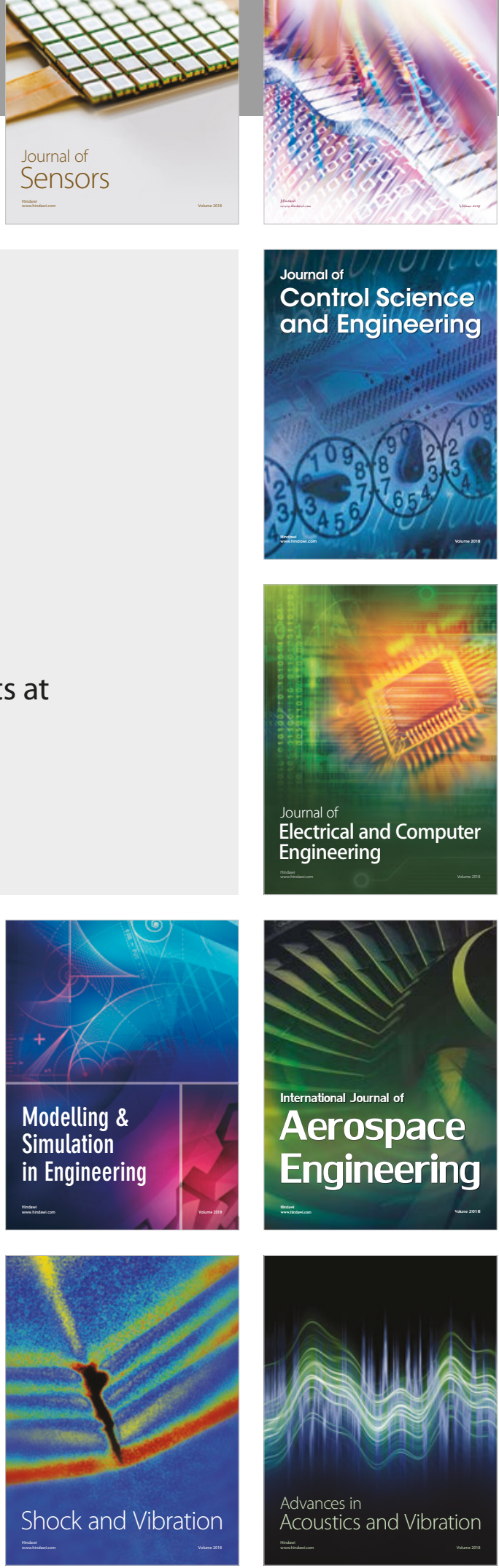